\title{
Poéticas de memoria y lugaridad: aproximaciones a la actual poesía de mujeres chilenas, argentinas y mapuche*
}

Poetics of Memory and Place: An Approach to the Current Poetry of Chilean, Argentine and Mapuche Women

\author{
Fernanda Moraga-García \\ Centro de Estudios Avanzados (CEA) \\ Universidad Andrés Bello \\ moraga.fer@gmail.com
}

Este trabajo plantea una revisión aproximativa respecto del campo poético actual de mujeres chilenas, argentinas y mapuche a partir de las posibles construcciones políticosimbólicas de memorias postraumáticas y su relación con diferentes lugaridades de y en la enunciación. Esto, en la comprensión de que la poesía sobrepasa lo estrictamente estético y se articula con acontecimientos históricos que provocan cambios sociales, culturales y políticos relevantes.

Palabras clave: Poesía, memoria, lugaridad.

This work proposes an approximate review on the current poetic field of chilean, argentine and mapuche women based on the possible politico-symbolic constructions of post-traumatic memories and their relationship with different places of and in the enunciation. This, in the understanding that poetry surpasses the strictly aesthetic and is articulated with historical events that cause relevant social, cultural and political changes.

Keywords: Poetry, memory, place.

* Este artículo forma parte del proyecto FONDECYT de Iniciación No 11150141. 


\section{Comentarios iniciales}

Si pensamos desde un punto de vista de una ordenación periódica de la poesía del Cono Sur, sin duda, podemos visualizarla en relación con momentos históricos de violencia. La poesía actual chilena y argentina permite ser comprendida a partir de las condiciones generadas por la instalación de las dictaduras militares en ambos países durante las décadas de los 70 del siglo pasado. Por su parte, la presente poesía mapuche, del mismo modo, admite ser reflexionada en vinculación con este hecho traumático, pero también desde otros acontecimientos genocidas, especialmente a partir de las intervenciones militares en Wallmapu ${ }^{1}$ a ambos lados de la cordillera, hacia fines del siglo XIX².

De esta manera, nos interesa hacer una aproximación al campo poético actual de mujeres chilenas, argentinas y mapuche a partir de las posibles construcciones de memorias de la violencia y su relación con diferentes lugaridades de enunciación. Para esto, me parece necesario comprender esta poesía como una producción cronotópica, ya que se trataría de memorias que establecen y densifican relaciones inevitables entre tiempos y lugares de la experiencia.

A esto se suma que la poesía construye tejidos artísticos que están conformados por cambios, aproximaciones, transformaciones, continuidades y rupturas (Nómez 2010: 421). Sin embargo, cuando se producen cambios o transformaciones epocales -como pasó con las dictaduras, las posdictaduras y las antiguas y permanentes invasiones a Wallmapu- hay que reconocer que se producen líneas dominantes que más que apartados generacionales corresponderían a promociones escriturales que tienen o manifiestan cierta construcción tendencial que actualmente, por ejemplo, tiene el nombre de "escritura de los hijos" o de la "posmemoria"3, para el campo chileno y argentino.

\footnotetext{
1 Wallmapu, que en la lengua de los mapuche significa "territorio circundante", es el nombre dado por los mapuche al territorio que histórica y culturalmente ocupan y que se extiende, por el sur, desde Chile hasta Argentina.

2 En el caso de Chile, esta ocupación de Wallmapu correspondería al primer intento de "Pacificación de la Araucanía". El segundo, indica Fernando Pairicán, sería el que se inicia a mediados de los 90 del siglo recién pasado y que perdura hasta hoy. El autor se refiere, siguiendo la lectura del libro Ralco irepresa o pobreza? (1999), de Domingo Namuncura, a la construcción de la represa hidroeléctrica Ralco en territorio pewenche en 1997: "Varias familias pewenche serían 'permutadas', es decir, expropiadas de sus milenarias tierras y enviadas a colonizar otras [...] El impacto sociocultural era improcedente y acabaron por reflotar las antiguas historias de vulneraciones que sufrieron nuestros abuelos y abuelas a lo largo del siglo XX" (2017: 4).

3 El concepto de posmemoria fue acuñado por Marianne Hirsch (1997) y se origina a partir de los testimonios de los sobrevivientes y familiares de las víctimas del genocidio de Auschwitz y hace alusión a la memoria transmitida por aquellas generaciones inmediatas y de filiación directa (hijos, nietos) con las víctimas del genocidio. En el caso del Cono Sur, se suele usar en relación a la memoria de la violencia heredada de las dictaduras y fundamentalmente se refiere a las producciones culturales (cine, documentales, literatura, etc.) elaboradas por estas generaciones de postrauma y que no necesariamente son de filiación sanguínea directa.
} 
Hablamos de una poesía que incluso ha sido relevada por los propios poetas de esta promoción y también discutida por una parte importante de la crítica académica (Bolte, 2016; Salomone, 2015; Peller, 2015; Sepúlveda, 2013; Urzúa, 2012; Bello, 2011; Mansilla, 2010; Nómez, 2009; Espinosa, 2006; Genovese, 2003; entre otras y otros más). Se trata especialmente de una poesía que, en términos generales, "inaugura", mediante relecturas del trauma del pasado dictatorial reciente, una nueva producción poética que construye "una memoria desprendida de la inmediatez, una memoria ligada, pero también autonomizada de su archivo de dolor, de su pantano de sufrimiento" (Genovese 2010: 73).

A partir de esta breve anotación acerca de la poesía reciente en esta zona fronteriza del Cono Sur, es que también nos interrogamos por otras posibilidades de relación entre memoria, lugar, afectos y poesía en la producción de mujeres. Pensamos que existen otros proyectos que no formarían parte de este campo de las representaciones "visibles" de la poesía que reelaboran la memoria postraumática. Algunas de estas propuestas, por ejemplo, no coincidirían con las problemáticas propias de las enunciaciones urbanasmetropolitanas -aunque estas sean residuales y marginales- como único referente de lugarización de la memoria, como es el caso de gran parte de la poesía mapuche y de otras como la poesía del sur o del norte en Chile y Argentina 4 . Existirían asimismo poéticas que no se ajustarían a lo que suele llamarse "generación" de los 2000, porque se trataría de proyectos literarios que vienen desarrollándose, en el sentido que nos interesa en este estudio, desde fines de los 70, los 80 y los 90 del siglo XX, hasta hoy, y que también circulan dentro de este campo artístico que, por momentos, solo pareciera ser ocupado o visibilizado por ideologías generacionalistas y centralistas ${ }^{5}$.

Al hablar de décadas o generaciones creemos que podría limitarse la comprensión de la complejidad del campo poético -aunque sí estoy de acuerdo en que puede ordenarse-, pudiéndose producir una borradura de otras experiencias particulares y colectivas que están en relación con dimensiones etarias, de género, de raza, de pueblo, regionales, etc., las que

4 Existen aportes importantes a los estudios de la poesía del sur-Patagonia (Chile-Argentina). Solo por citar algunos nombres, pienso en el chileno Sergio Mansilla y en el argentino Cristián Aliaga. Por el norte, en Chile, habría que destacar, entre otros nombres, a Walter Hoefler y por el lado argentino, a Santiago Sylvester y a Raquel Guzmán.

5 A esto habría que sumar la reedición de libros. A modo de ilustración, pensemos en La bandera de Chile (1991) de Elvira Hernández, reeditado en 2010; Sabor a mí (1973) de Cecilia Vicuña, reimpreso en 2007 o Estrellas de Chile para ti, una compilación de tres libros de Malú Urriola publicada en 2015: Piedras rodantes (1988), Dame tu sucio amor (1994) e Hija de perra (1998). También existen ediciones antológicas que recopilan libros o fragmentos de libros de diversas autoras que comenzaron a escribir en los 70, 80 o 90 del siglo XX. Ejemplo de esto son las antologías de la obra completa de las argentinas Tamara Kamenszain y Diana Bellessi, La novela de la poesía. Poesía reunida (2012), y Tener lo que se tiene (2009), respectivamente. En el caso de las poetas mapuche es diferente, porque ellas, en su mayoría, comienzan a publicar a partir del año 2000. Sin embargo, existen algunas reediciones como es el caso del libro Walinto (2001) de Graciela Huinao, el que fue nuevamente editado en 2008, en una versión trilingüe (mapudungún, inglés y español) y el poemario de Rayén Kuyeh, Wvne coyvn ñi Kvyeh. Luna de los primeros brotes (1996, autoedición en mapudungun y español) y que luego fue publicado en Italia (versión en mapudungun e italiano), en 2006. 
aportan nuevas especificidades y heterogeneidades al escenario poético. Por tanto, me gustaría referirme más que un ordenamiento por generaciones o décadas, a la coexistencia de diferentes proyectos escriturales que entran en el juego de las disputas, las tensiones y las aproximaciones en lo que, por ahora, se refiere a la poesía actual (Peller 2015: 6).

Realizado este alcance parcial a la poesía de mujeres en este comienzo de siglo, podemos decir que hay una amplia variedad de voces que hablan pertinente a los traumas del pasado y sus consecuencias en el presente. Entre las diversas estrategias que se utilizan se encuentran la pérdida de una comunidad y el posicionamiento de una memoria política como punto de anclaje desde el que los y las sujetos pueden rearticularse individual y colectivamente dentro de experiencias y espacios fragmentarios de la historia. Por su parte, la poesía mapuche señala una memoria política, cultural e histórica postraumática, que establece vínculos desde el presente con hechos históricos de violencia límite o extrema ocurridos tanto en América Latina como en el territorio mapuche, marcando la reproducción del horror colonialista hasta hoy.

Una buena parte de las prácticas poéticas mencionadas más arriba -incluyendo por supuesto la mapuche- desoculta la relación consensuada, no solo entre las dictaduras y las democracias neoliberales que le han sucedido, sino también lo hace con los pactos de silencio entre estas mismas democracias y la producción institucional de la memoria histórica. En contra de esta narrativa pacificadora y excluyente, estas propuestas poéticas desestabilizan el discurso postdictatorial al posicionar valores afectivos y políticos irreductibles al intercambio entre olvido y memoria. Por tanto, para referirnos a la poesía actual de mujeres dentro de esta zona de triple fronteras -Chile, Argentina y Wallmapu- no se puede desatender este común calificador que las atraviesa: la violencia del terrorismo de Estado. Esta última sería la filigrana que se reitera y que para Isabel Piper correspondería a la "retórica de la marca" (2005: 13), de una herida que permitiría que,

[I]a memoria [tenga] a la vez el potencial de fijación y subversión, constituyendo, por tanto, un espacio privilegiado para entender los procesos de disputa y construcción hegemónica de versiones del pasado, las identidades en juego y los intentos de elaboración de hechos violentos. Al mismo tiempo permite visualizar las condiciones de una política del recuerdo, entendida como la articulación de voluntades que genera condiciones de posibilidad para la construcción de saberes, afectos e identidades sobre el pasado y que están siempre abiertas a re-significación (Piper, Fernández e Íñiguez 2013: 23-24. Las cursivas son nuestras).

Esta retórica de la herida que posibilita una insubordinación de la memoria en cuanto esta se construye como política de la memoria, suministra nuevas reflexiones de los restos, las ausencias y las estridencias de las historias traumáticas en el intento de resignificar un pasado, intervenirlo y desmontarlo desde la crisis de un presente. Más aún, el pasado traumático no solo 
se reapropia por medio de nuevas lecturas y alegorías que lo presentizan, sino que a él se añade la intimidación de la jerarquía de un tiempo y un lugar neoliberalizado.

Así entonces, en estos contextos postraumáticos, la poesía realiza diferentes traducciones de la violencia de pasados recientes y antiguos a partir de un presente activo, lo que supone abordar determinadas problemáticas o sentidos críticos del discurso poético. Por ahora nos concentraremos en dos, debido a su relevancia dentro de las facturas poéticas a las que aludimos: la memoria y su lugaridad.

\section{En torno a la memoria y la lugaridad poéticas}

No cabe duda de que la problemática de la memoria es una de las cuestiones más apremiantes del contexto actual. La experiencia traumática del terrorismo de Estado en países como Chile, Argentina y Uruguay en la década de los 70 y 80 del siglo XX, situó la discusión alrededor de la memoria, especialmente respecto de las políticas de la memoria, en el eje de los debates políticos, culturales y de la reflexión académica. Sin embargo, sabemos que la cuestión de la memoria en el Cono Sur -y en América Latina- tiene una temporalidad propia que se inicia con las sociedades indígenas, las que sufren un primer corte externo con la expansión del mundo europeo. De aquí arranca un sinnúmero de memorias de la violencia colonialista y militar, las que influyen en las conformaciones y en las diputas por las identidades y sus memorias.

La poesía al construirse como un desvío de la norma discursiva, potencia, mediante los soportes lingüísticos, visuales, auditivos, etc., una traducción cultural, ética, y política "de las condiciones de su contexto, de la subjetividad individual y colectiva, de los saberes sociales y su circulación, de los imaginarios sociales, logrando cifrar aquello que se supone indecible" (Arpes y Gasel 2011: 98). La articulación de la memoria a los soportes del lenguaje poético, especialmente al recurso de la palabra, permite reubicar la ferocidad del acontecimiento histórico ${ }^{6}$ en una perspectiva que reinterpreta el momento mismo, a la vez que se vincula a las experiencias de sus devastadoras consecuencias en el presente por medio de nuevas complejidades y traducciones del sentido. Por tanto, la reelaboración de la memoria en la poesía -como también en otras producciones artísticas- está interesada en las posibilidades políticas del cómo se puede leer, testimoniar o traducir un pasado traumático. $Y$ no tan solo eso, sino que, por sobre todo, resistir y denunciar las consecuencias de esta violencia en el presente, y de paso (deliberado) interponerse en las reproducciones pactadas en acuerdos que, del trauma y sus efectos hasta hoy, realizan las versiones oficiales de la memoria. En este sentido, me parece relevante la pregunta que se plantea Nelly Richard:

\footnotetext{
6 Aquí, pongo el valor crítico que tiene la reconstrucción de la historia, que también es la reconstrucción de la memoria, porque no se pretende una matriz objetivada de un momento unificado o aislado en un pasado antiguo o reciente, sino, acentuar la movilidad y proyección del acontecimiento histórico lo que le permite eludir toda neutralidad actual que le puede producir su fijación temporal y espacial.
} 


\begin{abstract}
¿Por dónde rastrear la fragmentariedad de identidades revueltas, en crisis de pertenencias, que no se reconocen en ninguna de estas dos edificaciones lineales -ni en el serenamiento oficial del pasado consensuado de la memoria de la transición ni en el dogma partidario del recuerdo militante de la izquierda- porque ambas construcciones esquematizan el relato de un pasado demasiado seguro del ordenamiento y la cohesión de sus motivos? (2010: 19).
\end{abstract}

\title{
Influencia
}

Para Richard la producción de una memoria política que tienda a difuminar esta dicotomía se vincula a lo residual, es decir, a la presencia de sentidos que se encuentran al margen o que no son visibilizados por los discursos oficiales o que bien son considerados como suplementos dentro de los mismos y que, sin embargo, al ser (auto)validados facilitan una crítica y una resistencia a los discursos hegemónicos. Estos residuos o restantes que operarían de manera insubordinada dentro de la memoria representativa, tendrían dos responsabilidades cruciales: una "responsabilidad ética [que debe] oponerse a los flujos de desmemoria" (2017: 65) y una "responsabilidad crítica" que correspondería al ejercicio de una "contrainterpretación" de aquella memoria simplificadora de la violencia, de esa memoria que se produce para el equilibrio de las partes. Ambas perspectivas de la memoria cobran relevancia para este estudio, porque coincidimos en que la memoria, en los textos poéticos, construye y se reconstruye como material crítico y ético de sedición ante los relatos elaborados por las historias oficiales de las posdictaduras.

Aludir a la memoria como producción crítica y ética, es referirse a ciertas políticas de la memoria que involucran dislocaciones conceptuales que se producirían a partir del parentesco entre historia y ficción, en cuanto una y otra están atravesadas, entre otras cosas, por la imaginación, la traducción y la interpretación. En esta dependencia, la poesía y el arte en general, establecen una función política para la compleja interacción entre las representaciones estéticas y las representaciones de la historia. Los campos poéticos que exploramos disputan esos sentidos políticos centrándose, como ya se mencionó, en las consecuencias catastróficas que la experiencia traumática y la victoria de su violencia tienen hasta ahora.

La fuerza simbólica de resistencia y subversión de la memoria radicaría en su potencial político como lugar de conocimiento. Sin embargo, esto en sí mismo no asegura su carácter transformador, sino que depende de la capacidad que puedan tener sus prácticas, entre ellas la poesía, de problematizar las versiones hegemónicas vigentes en el actual orden social (Piper, Fernández e Íñiguez 2013: 20). Al mismo tiempo, este potencial no puede ejercerse en una dimensión solo temporal de la memoria política, ya que su arraigo a algún espacio es ineludible. Por tanto, estas reescrituras poéticas de la memoria tienen o son parte de un lugar, es decir, son memorias lugarizadas. 
El pasado es imposible sin la evocación del lugar, ya que este interviene de forma inmediata en la dimensión de la identidad. El espacio -sea urbano, rural, geográfico, corporal, simbólico, virtual, público o privado- está conformado por un sinnúmero de lugares con y en los cuales los/las sujetos tienen experiencias, identificaciones o desidentificaciones producidas por relaciones de afecto, de miedos, de conflictos, de seguridad-inseguridad, entre otras. Incluso en el actual escenario de una imponente globalización tecnológica, virtual y de masivos medios de comunicación, la urgencia de los lugares forma parte del fortalecimiento de la experiencia sensible del sujeto y/con su comunidad ante la amenaza permanente de una desintegración social (Seguel 2001: 18). En esta perspectiva, la lugaridad emerge como la relación de construcción del habitar que un sujeto -o una comunidad- mantiene con un lugar, en otras palabras,

[I]o que somos tiene un marcaje de lugaridad, que nos hace ser lo que creemos ser y lo que los otros creen que somos; lugaridad como contexto simbólico pensado-sentido-vivido, producido desde la interpretación colectiva de las historias culturales que definen imágenes identitarias plurales y diversas (Vásquez y Pérez 2009: 654).

La elaboración de memorias lugarizadas podría convertirse, asimismo, en un relato de resistencia y problematización de la memoria neutralizada por los discursos y las acciones de la institucionalidad. También podría construirse como un relato de diálogo y discusión en el campo de las políticas de la memoria localizada que se forma a contrapelo de esa neutralización. En estos sentidos pensamos al proponer que el lugar y su lugaridad son políticos, porque en ellos se relacionan los sujetos y establecen su pertenencia, no pertenencia o despertenencia; por tanto, el lugar no es un espacio que se ocupa o desocupa, sino que se construye. De aquí la importancia del lugar en la memoria.

En nuestra perspectiva, la poesía como espacio de sentidos estéticos, éticos y políticos pone en valor estas relecturas lugarizadas de las memorias. A contrapelo de los relatos pactados por las posdictaduras, la poesía promueve el restablecimiento de memorias residuales que se resisten a la administración de sus saberes. Mediante la densidad artística de su lenguaje, es posible encontrar marcas que legitiman experiencias de memorias culturales y políticas relegadas, interrumpidas o silenciadas; poniéndolas en circulación. En este sentido, nos interesa proponer la especificidad de la poesía como una forma particular de lugarizar las "memorias perturbadoras" (Portelli 2013).

La heterogeneidad de respuestas o cuestionamientos que un campo poético puede dar a los contextos - pasados y presentes-, no puede comprenderse como una réplica o una interrogante directa o automática que traduzca el texto en función del contexto. Por el contrario, la imagen poética nos mantiene "en una zona de sospecha, de cautela, de incertidumbre, de falibilidad posible" (Hoefler 2012: 13). Ni la poesía, ni la literatura, ni el arte en general reflejan o sustentan por sí mismos los vaivenes contextuales, probablemente solo puedan exorcizarlos, denunciarlos, traducirlos o problematizarlos: 
[S]ospechamos que todo discurso es ficción, en tanto es siempre una representación diferida o desplazada, puesto que el lenguaje no opta [casi nunca] por el único signo posible de las cosas o de los hechos, y es en la poesía donde este excedente o deuda de sentido se manifiesta en plenitud (8).

Por mi parte, asumo esta actitud poética del lenguaje como una contestación residual productiva ante una crisis postraumática y ante la disolución de los sentidos de la experiencia que esta crisis provoca. Pensamos que es relevante, entonces, valorar la fragmentariedad del lenguaje como emancipaciones del mismo, la que muestra y no describe, las "secreciones" presentes de la violencia, posicionándolas en una nueva ordenación de los sentidos. Además, esta radicalidad de la imagen poética a la vez que se construye con esos desechos, restituye la vitalidad de los residuos de la memoria y del lugar organizando su infiltración política en el espacio de la memoria oficial. Comprendemos así, que la poesía es un potencial de subversión, de igual modo que nos planteamos la producción de memorias lugarizadas en el actual escenario poético de comienzos de siglo XXI en la frontera compartida y resistida entre Chile, Argentina y Wallmapu.

\section{Notas sobre el campo poético actual}

A partir de una breve exploración del escenario vigente de la poesía de mujeres chilenas, argentinas y mapuche, nos damos cuenta que presenta, además de una identificable enunciación posicionada en la subjetividad de una primera persona (singular y plural); sujetos abrumados con las intimidaciones del olvido. La lógica del olvido que en posdictadura se inaugura en el período de transición a la democracia, especialmente en Chile durante los años 90 del pasado siglo y que formó parte de la política de los acuerdos, enfatizó la disolución de la subjetividad colectiva7. A esto se adicionan las políticas económicas que funcionan como una herramienta cooptadora del recuerdo, produciendo borraduras de la memoria a través de la mediatización de la cultura y su transformación en bien de consumo ${ }^{8}$. Por lo tanto, para la poesía de los años

\footnotetext{
7 Si bien en Argentina, en los 80, el período llamado "transición a la democracia" se diferenció del proceso chileno en los 90, debido a que en el país trasandino se produjo un clima crítico y antidictatorial que llevó a que se juzgaran inmediatamente a los responsables de los crímenes cometidos en dictadura, mientras que en Chile el pacto de los acuerdos y los consensos encabezó el período; la lógica del olvido de todos modos se hizo presente. Al respecto Marina Franco afirma: "El hecho de que el proceso argentino sea considerado ejemplar en términos de una temprana 'justicia' y 'verdad' sobre los crímenes ha desdibujado en la memoria social, y en los relatos académicos, buena parte de la contingencia histórica, de las relaciones de fuerza cambiantes que llevaron a ese desenlace, así como un amplio abanico de elementos de continuidad en cuanto a las representaciones sociales y políticas sobre lo sucedido en la Argentina en los años 70" (s/p).

8 En este sentido, habría que comentar que la política ideológica del "libre mercado" -el monetarismo o neoliberalismo- funciona como eje programático desde mediados de los
} 
90 y 2000, es la memoria la que tiene la capacidad de restablecer los vínculos significativos entre el/la sujeto, su comunidad, su temporalidad y su espacio.

Por esta razón, los textos poéticos tienden a validar lo que hay en la ausencia, en la contradicción, y en el mundo privado de las memorias y de los lugares como restantes del lenguaje de los pactos de blanqueamiento de los horrores naturalizados por las dictaduras y por los colonialismos, hasta nuestros días. A partir de aquí ilustraremos lo anterior con algunos ejemplos poéticos. Se destaca en estos "ejercicios" poéticos de traducción e interpretación de la memoria de violencias, la huerfanía y la carencia de respuestas están grabadas en el trauma familiar (Quílez 2014: 58). Muchas veces estos sentidos de la memoria son asumidos desde una infancia cercada por el filo de una dictadura que actuaba como una "dimensión desconocida" (Fernández: 2016)9 ${ }^{9}$. En este sentido, y citando la escritura de Ivonne Coñuecar, lo desconocido se experimenta como una violencia que no se comprende:

no supe de mi burguesía hasta que vi / no todos comían todos los días / que a otros les molestaba que yo tuviera siempre comida mientras yo odiaba que la comida sobrara en casa. así fui confundiéndome por las calles. los lunes en el colegio cantábamos vuestros nombres valientes soldados que habéis sido de Chile el sostén / nuestros pechos los llevan grabados / lo sabrán nuestros hijos también. pero no supimos nada / ni de los muertos / ni de la crisis del ochenta y dos / ni de la censura/ ni de las protestas / ni de las universidades / ni de los que cerraron sus cortinas (2014: 101) ${ }^{10}$.

De la misma manera, esta "dimensión desconocida" que se lugariza en la memoria opera como una estética de la orfandad o el desamparo: "¿y me lloraste alguna vez sobre mi tumba madre?/yo tuve una tumba pequeña/ mi cuerpo no pasó más frío/ ¿por qué mi padre se exilió? ¿murió allá lejos? ¿quiso volver?/¿entonces de dónde me trajiste madre cuando nadie elegía nada en este país?" (95).

años 70 en adelante en el Cono Sur. Sin embargo, esta política económica establecida por las dictaduras chilena y argentina se ha visto fortalecida, especialmente en Chile, por los gobiernos de las posdictaduras, provocando que su normalización traspase lo políticoeconómico, e impacte a todo el campo cultural e, incluso, que se introduzca en la producción de la intimidad-subjetividad. En relación con esto, Luis Cárcamo-Huechante plantea que el libre mercado, como "'ajuste estructural' fue [y es] también un ajuste cultural y/o un giro simbólico. [...] el libre mercado se constituye en un discurso cultural que, a partir de un conjunto de intervenciones retóricas e imaginarias se despliega hegemónicamente en la sociedad..." (Tramas del mercado 17).

9 Aquí utilizo el título del libro de Nona Fernández, La dimensión desconocida (2016), el que a su vez toma el nombre de una serie de ciencia ficción estadounidense que se exhibía por la televisión en los años 70. La temática del relato de Fernández gira alrededor de la historia de un torturador ("El Papudo") que en los años 80, en Chile, confiesa, en una entrevista con la periodista de la revista Cauce, Mónica González, sus crímenes, y de paso delata a sus compañeros de armas.

10 El formato, las barras y las cursivas corresponde al original. 
Otra autora chilena, Florencia Smiths, ensaya una poética narrativa (auto) biográfica -igual que Coñuecar- en la que se potencia un lenguaje político que pueda traducir las complejas y fragmentarias imágenes de la infancia: "Es imposible que se escriba tal como se vio, aun es imposible que se la deje ver, porque está y permanece allí: la estafa, la carencia, ranura de párpados y boca descompaginada, grietas en la sonrisa que ya no ríe, el surco que deja una silenciada cuando se le escarba o factura la muerte" (2008: 17).

En otro soporte de la memoria poética, la argentina Andi Nachón promueve una escritura mucho más relacionada con el "relato de filiación", término que más bien es usado para la narrativa, pero que pensamos es oportuno en esta escueta extrapolación. Su libro La III guerra mundial (2013) rastrea un lugar más directo de la memoria de la dictadura argentina, siempre a partir de una voz situada en la infancia. El lugar ya no es la casa, sino el viaje y especialmente el auto familiar, el que se transforma en un lugar de encierro y de interrogantes, no desde una segunda fila del asiento trasero, sino desde la mirada y cercanía que puede tener, en este caso, la copiloto. Se trata del viaje como tentativa de fuga del horror: "Mapas, rutas, accesos cortados: crecemos navegando así /nuestra fe en la catástrofe [...] Soy buena copiloto, aunque no lea los mapas y pasen/ los carteles a velocidad de la luz" (11-12).

Una de las motivaciones para que estas nuevas voces poéticas asuman un relato "particular" de la memoria, responde, de alguna forma, a que "ha desaparecido la culpa personal" (Baer 2006: 119) en relación con la violencia de las dictaduras y su fatídica herencia.

Otro espacio relevante de filiación es la ciudad, que, en opinión de Magda Sepúlveda, la poesía de los años 2000 se caracterizaría por representar la fragmentación de la ciudad en lugares marginales. Sepúlveda destaca, entre otros: la "disco" -como punto de encuentro y exposición de los cuerpos-, el barrio o la barriada -como representación de una comunidad desperfilada de la clase- y los paraderos de micros -como territorios de subjetividades populares- (2013: 239). Solo a modo de ejemplo, cito un fragmento del libro Gran Avenida (2005) de Gladys González:

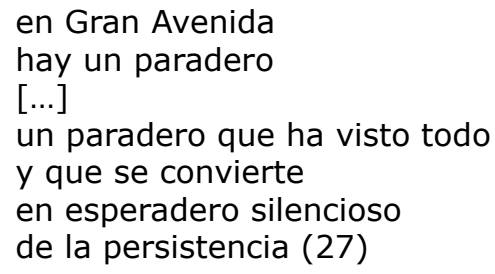

Un aporte imprescindible a este campo artístico es aquella poesía que, de diversas maneras, da "continuidad" a ciertas líneas de sentido crítico de las promociones anteriores. Hablo de una poesía que ya se viene desarrollando desde las dos últimas décadas del siglo $X X$ y que tiene proyectos vigentes hasta hoy. Ese es el caso de, y por citar nada más que un puñado de nombres entre chilenas, argentinas y mapuche: Elvira Hernández, Rosabetty Muñoz, Malú Urriola, Veróniza Jiménez, Alicia Genovese, Diana Bellessi, Tamara Kamenszain, Sonia Caicheo y Rayen Kuyeh, entre muchas 
más. Estas escrituras, además de contribuir con diferentes perspectivas y facturas poéticas en relación con la poesía más joven, marcan la obstinación de la memoria, ya que en sus textos subyace con fuerza la conciencia de que la dictadura ha triunfado, fundamentalmente, por medio de la actual cristalización depredadora del "libre mercado" y su consecuencia directa: el fraccionamiento de la comunidad social. La poeta chilena Elvira Hernández nos relata de esta forma el trágico presente de esta victoria:

¿Encontraremos los pelos de la vergüenza

Las escamas óseas de una verdad agrietada

La vértebra de nuestra historia?

¿Estará en algún lugar del territorio

la mano de la justicia o solo seremos pasto

Y gente que escobilla sus trajes? (190) ${ }^{11}$.

En un sentido diferente a lo que revisamos en estas notas, la argentina Alicia Genovese entra también en el imaginario de una lugarización de la memoria en el presente. Aunque el trayecto de su escritura se arma principalmente mediante sutiles y potentes filiaciones familiares y no necesariamente desde una memoria arraigada en un postrauma histórico, me parece importante mencionarla por dos motivos. Uno de ellos es que el campo de la poesía permite deslizamientos que le dan aún mayor espesor y diversidad a la posibilidad de interrogar la memoria poética actual. Y la otra razón es porque su escritura, a partir de esta memoria diferenciada en la producción del recuerdo de la violencia histórica en la poesía de mujeres, visualiza el presente como un "espacio vacío": "el maleficio,/ el presente, sin promesa. [...] basura y más basura / en el suburbio de la evocación, / carcoma del cuerpo subastado" (2015: 19).

En esta perspectiva e intentando darle una vuelta política aún más amplia y visibilizadora a la relación poesía-memoria-lugar en el actual campo poético, no podemos eludir las reescrituras de la memoria en las producciones artísticas mapuche.

En la poesía mapuche habría otros "horizontes históricos" (Rivera Cusicanqui citada por Acossatto 2017: 168) de la memoria traumática como insumo crítico y ético. Sin duda, la ocupaciones bélicas y civiles de los territorios mapuche en la segunda mitad del siglo XIX, y que son oficialmente conocidas como la "Pacificación de la Araucanía" en Chile y "La conquista del desierto" en Argentina, constituyen un marco interpretativo que permite comprender, no solamente, la violencia histórica de extendido alcance para la sociedad mapuche, sino también "la emergencia de sujetos políticos a partir de diferentes horizontes temporales que complejizan las constituciones identitarias" (Acossatto 2017: 168) en el presente campo de la poesía mapuche.

La reelaboración actual de una memoria traumática en esta poesía no obedece a la simple recuperación de un momento histórico devastador, sino a políticas de la memoria sobre y de un pasado que se reelabora como

11 Este poema fue escrito en 2001 y publicado en 2016. 
conocimiento, reflexión e interpretación estético-política del acontecimiento. Esta reelaboración se realiza desde un presente, el que además está cargado de otras violencias que van produciendo nuevas y diferentes identificaciones con el espacio y la subjetividad. La producción artística mapuche de hoy 12 reconstruye lugarizaciones de memorias en articulación a una interculturalidad crítica que interviene la historia, la memoria y los afectos colonialistas del sistema oficial. Por tanto, pensamos que las políticas de la memoria en la poesía mapuche de estos momentos mantienen, como dice Beatriz Sarlo, "una relación de posteridad [que] también tiene conflictos y contradicciones características del examen intelectual de un discurso del pasado y de sus efectos sobre la sensibilidad [en el presente]" (2012: 128).

El sondeo de las estrategias de la memoria en esta poética es inexcusable al momento de comprender la permanencia del pasado traumático por medio de las generaciones. Lo es, no solo porque estas escrituras se despliegan como compromisos para la preservación y reactualización de la memoria colectiva, sino porque igualmente suelen transgredir y resistirse a la continuidad de la violencia colonialista. También lo es porque la rememoración individual, por otra parte, proporciona una perspectiva acerca del recuerdo colectivo. Sin embargo, los diversos puntos de vista y los diferentes enfoques asumidos por las enunciaciones en los poemarios pueden entrar -y algunos entran- en tensión con las necesidades del colectivo mayor, el que tiene por objetivo conservar la unidad, la permanencia y el equilibrio de la sociedad mapuche. En este último sentido es que poéticas como la de Adriana Pinda irrumpen al posicionar una sujeto anclada a la experiencia de "lo mestizo", en cuanto a que la enunciación de sus poemas es producto de una historia de violencias que se inicia en el pacto patriarcal entre indígenas y españoles en siglo XVI ${ }^{13}$. Esta enunciación, especialmente en su libro Parias zugun (2014), se simboliza la figura de la Malinche como representación de la exclusión y del tráfico de mujeres indígenas: "Malinche le dijeron / la maldijeron Malinche / la mujer lengua / la maíz lengua / la vi/ y las vi a todas/ llagas vivas / las lenguas hechiceras / las lenguas hechizadas / las vi / $\operatorname{arder}^{\prime \prime}(46)$.

En una línea similar, Liliana Ancalao, poeta mapuche del lado argentino, en tanto que en su libro Mujeres a la intemperie (2009) la lugaridad de la memoria está en el cómo sobrevivir en un tiempo urbano que es resultado de los cortes históricos impuestos a los mapuche. En este sentido, el libro sitúa el ritual de la conversación como un puente que comunica dos bordes colectivos. Allí se manifiesta el espacio de la sabiduría y del conocimiento

\footnotetext{
12 No solo la poesía reelabora memorias políticas de esta violencia colonialista, sino también el arte visual, el cine, la narrativa, la música y la performance mapuche.

13 Las posibilidades de una reescritura de la memoria traumática en América Latina, se amplía y se hace compleja aún más en el tiempo y en el espacio: el acontecimiento traumático protagonizado por la invasión europea en el continente a partir del siglo XV cuyas consecuencias colonialistas y racializadoras son materia de discusión académica, de producciones artísticas, de movimientos sociales, de resistencias identitarias y políticas, hasta hoy. Al respecto Millaray Painemal y Andrea Álvarez, afirman la importancia de "reconocer el 'efecto persistente del trauma histórico', como daño de larga data que se reproduce en los pueblos originarios desde la Conquista, y que es resignificado en la memoria colectiva transmitida intergeneracionalmente y [que] se reifica ante nuevos acontecimientos violentos y traumáticos contemporáneos" (2016 80).
} 
entre la memoria ancestral de mujeres y una memoria a la intemperie de mujeres mapuche en el presente: "el viento siempre vuelve / quiere rendirnos a nosotras / probarnos las raíces/ llevarse algunas / arrastradas / o girando/ yo prefiero esas matas livianas / a estos huesos espesos / que reventarán contra el cemento" (32). Por último, quiero citar, dentro de estas condiciones políticas del proyecto de la memoria y el lugar enunciativo de la poesía mapuche de mujeres, los siguientes versos del libro Exhumaciones (2010) de Yeny Díaz Wentén: "¿Qué bestia ha roto la constelación justa de las montañas / y tiró tu carne a las ciudades?" (66).

Estas tres poetas y otras como la ya mencionada Ivonne Coñuecar, Roxana Miranda Rupailaf, Daniela Catrileo, Maribel Mora Curriao y Eliana Pulquillanca, entre muchas más, contribuyen con políticas de la memoria que muestran las consecuencias y las transformaciones que ha sufrido el pueblo mapuche con las historias de violencias. La poesía mapuche construye una lugaridad de la memoria político-simbólica excluida -especialmente la de mujeres ${ }^{14}{ }_{-}$, no tan solo del registro emblemático de generaciones descendientes de genocidios -lo que obedece a un pacto racista-, sino también por el repertorio de memorias disidentes de este registro emblemático, como lo es, en muchas ocasiones, el mismo campo poético.

\section{Comentarios finales}

Un primer comentario al que me gustaría hacer referencia es que estas poéticas que circulan con mayor o menor visibilidad en esta triple frontera del campo cultural del Cono Sur son manifestaciones artísticas de una memoria crítica que interroga el pasado o los pasados tanto conocidos como invisibilizados o neutralizados, para producir nuevas interpretaciones o traducciones del sentido mediante interrupciones y contradicciones en torno a la representación valorativa de la memoria.

Un segundo comentario es que esta poesía realiza una construcción del lugar de la memoria que va entre lo íntimo y lo político, es decir, una lugaridad de la memoria como "política de la intimidad". Con política de la intimidad comprendo un espacio de lo íntimo no como aquello que queda sometido a un erróneo propósito de que el dominio de lo privado estaría por sobre lo colectivo o se restaría de él. La política de la intimidad es una estrategia fundamental de la producción de la experiencia, en cuanto instala el irrenunciable sentido de la memoria como una interrelación entre tiempos, lugares y subjetividades. A esta lugaridad política de interacciones íntimas de la memoria apuntan las narrativas poéticas a las que aluden estas notas.

Estas formas artísticas traman variaciones de la subjetividad que posibilitan comprender, a mi juicio, que sus lugaridades de la memoria corresponden a una noción de "lugar" como espacio de creación y recomposición de lazos

14 En Chile las autoras mapuche han tenido una "mayor visibilidad" en esta última década, a diferencia de sus pares en Argentina, las que muchas veces han quedado subsumidas a una producción poética de la Patagonia. Sin duda, esto obedece a diferencias en los procesos históricos, políticos y literarios en ambos países y en Wallmapu. 
afectivos de sujetos dañadas/os. Por tanto, entiendo la lugaridad de la memoria en un doble sentido: como un lugar físico - sea cual sea, incluyendo un posible carácter fugaz, intermitente, permanente o ausente- y como lugaridad de la enunciación, es decir, un habla posicionada en la experiencia y en el saber que le otorga esa experiencia. De esta forma, entonces, pensamos que la memoria lugarizada o la lugarización de la memoria se constituye en la articulación de ambos sentidos, los que no tienen por qué mantener una relación de coherencia entre sí, ya que se construyen de manera provisoria, parcial, en conflicto o en contradicción, lejos de una concepción estable o invariable de sí mimas y del sujeto o comunidad que las proyecta en los textos.

La poesía de mujeres del período que nos ocupa -y estoy segura que la de los hombres también- manifiesta un conocimiento respecto de esta interdependencia sujeto-colectivo-lugar y afecto, es su condición ética con la que entran al campo de disputas por la memoria traumática. Los textos señalan memoria poética que vuelve repetidamente hacia el pasado pendiente, abriendo así la posibilidad de hurgar en los anales de la historia de las dictaduras, de las posdictaduras y de las violencias colonialistas. En el caso de las mapuche, suman a lo dicho un lugar político y ético de la memoria que es impostergable: el desmontaje de la historia oficial para dar cuenta del dificultoso y contradictorio trayecto de destierro y, del mismo modo, mostrar las huesas que ha dejado su violencia. De esta manera, es que estas poéticas asumen los dos compromisos mencionados más arriba y que son propuestos por Nelly Richard: la responsabilidad ética y la responsabilidad crítica, ya que conforman un itinerario simbólico con propósitos políticos y éticos que, evidentes o no, entran en espacios de poder en los que potencian la resistencia.

La poesía que reseñamos, más que reunirse en torno a la violencia propiamente tal, se concentra en los sentidos, como ya dijimos, de las políticas de lo íntimo y en las consecuencias que los diferentes hechos traumáticos han tenido en el presente. Son escrituras que no reproducen el pasado sino que lo que les importa, es el cómo leerlo desde el presente. Por tanto, se trataría de propuestas literarias que dan cuenta de un "saber de la memoria" (Waldman 2006: 12) y de sus diferentes elaboraciones, en tanto que tienen diversos conocimientos (y lugaridades) de enunciación.

Un tercer comentario que me interesa apuntar brevemente es que la poesía de la que hablamos es una práctica artística que rastrea "lo fragmentario, lo ambivalente, lo autorreflexivo, lo irónico, borrando fronteras entre la verdad y el simulacro" (Quílez 2014: 69). También, desde un punto de vista de la identidad, exploran tiempos pasados y orígenes sesgados debido a las secuelas dejadas por las violencias, principalmente la poesía mapuche. Finalmente para este tercer comentario, una nota casi al margen: los desenvolvimientos de la memoria en los textos se desplazan interactuando, debido a la potencialidad plástica del lenguaje poético, con lo narrativo y lo visual, con la intertextualidad, los subtextos, la parodia y lo (auto)biográfico.

Y cuarto, me parece necesario tener en cuenta, a la hora de explorar las memorias y sus lugares de subversión, que también existen otras formas de lugar y otras formas de memoria (otras estéticas de la poesía) que funcionan 
de manera más oblicua con las memorias traumáticas, lo que no significa que no sean memorias políticas emplazadas en lugares estratégicos desde donde amplían el campo poético con nuevas propuestas y lecturas de la realidad. Digo esto no porque toda poesía, solo por el hecho de nombrarse como tal, sea o deba formar parte de un campo cultural que se precia de tener valor estético, sino porque es imposible dar cuenta de una totalidad.

Lo importante es intentar no ejercer una borradura con otras producciones que podrían ser parte de esta trama poética, por lo que creemos es necesario imaginar que pueden hallarse otras producciones que, hasta ahora, desconocemos y que probablemente circulan dentro de contextos más locales y periféricos. Por último, sabemos que estas producciones poéticas de la memoria no son homogéneas y que tampoco obedecen a condiciones contextuales homogéneas, sino que son el resultado de articulaciones históricas y políticas individuales, colectivas, locales, nacionales y/o regionales. Articulaciones fundamentales que se encuentran en desarrollo en un estudio más amplio.

\section{Obras citadas}

Acossatto, Romina. "Colonialismo interno y memoria colectiva. Aportes de Silvia Rivera Cusanqui al estudio de los movimientos sociales y las identificaciones políticas". Economía y Sociedad, XXI. 36 (2017): 167-181. Impreso.

Ancalao, Liliana. Mujeres a la intemperie. Pu zomo wekuntu mew. Buenos Aires: El Suri Porfiado Ediciones, 2009. Impreso.

Arpes, Marcela y Gasel, Alejandro. "La escritura literaria del trauma y las deconstrucciones de los mitos históricos en el territorio de la literatura argentina actual". Revista de Humanidades 24 (2011): 97-114. Impreso.

Baer, Alejandro. Holocausto. Recuerdo y representación. Madrid: Losada, 2006. Impreso.

Cárcamo-Huechante, Luis E. Tramas del mercado: imaginación económica, cultura pública y literatura en el Chile de fines del siglo veinte. Santiago: Editorial Cuarto Propio, 2007. Impreso.

Coñuecar, Ivonne. Patriagonia. Catabática, Adiabática, Anabática. Santiago: LOM Ediciones, 2014. Impreso.

Díaz Wentén, Yeny. Exhumaciones. Los Ángeles, Chile: Camino del Ciego Ediciones, 2010. Impreso.

Fernández, Nona. La dimensión desconocida, Santiago: Literatura Radom House, 2016. Impreso.

Franco, Marina. "La 'transición a la democracia' en la Argentina frente a las cristalizaciones de la memoria". Caravelle 104 (2015): s/p. Web. 3 de septiembre de 2017.

Genovese, Alicia. La contingencia. México: FOEM, 2015. Impreso. . "Entre la ira y el arte del olvido: testimonio e imagen poética". Recordar para pensar. Memoria para la democracia. La elaboración del pasado reciente en el Cono Sur de América Latina. Fundación Henri Böll Cono Sur. Santiago de Chile: Ediciones Böll Cono Sur, 2010: 69-76. Web. 5 sept. 2017.

González, Gladys. Gran Avenida. Santiago: La Calabaza del Diablo, 2005. Impreso. 
Hernández, Elvira. Los trabajos y los días. Antología. Santiago: Penguin Random House, 2016. Impreso.

Hoefler, Walter. Presuntas re-apariciones. Poesía chilena: poemas 1973-2010. La Serena: Editorial Universidad de La Serena, 2012. Impreso.

Nachón Andi. La III Guerra Mundial. Buenos Aires: Bajo la Luna, 2013. Impreso. Nómez, Naín. "La poesía chilena moderna: de sus orígenes y continuidades y rupturas". Ed. Manuel Jofré. Un mar en una gota de agua. Nuevas visiones sobre la poesía chilena. Santiago: Facultad de Filosofía y Humanidades, Universidad de Chile, 2010: 421-442. Impreso.

Painemal, Millaray y Álvarez, Andrea. "Construyendo herramientas descolonizadas: prevención de violencia con mujeres mapuche". Millaray Painemal y Andrea Álvarez (comp.) Kyanq'ib'il xu'j b'ix kyanq'ib'il qxe'chi. Tuwün pu zomo. Mujeres y pueblso originarios. Luchas y resistencias hacia la descolonización. Santiago: Pehuén/CIIR, 2016: 72-82. Impreso.

Pairicán, Fernando. "A 20 años de Lumaco: una ruptura histórica". Le Monde Diplomatique 186. Chile (julio de 2017): 4-5. Impreso.

Peller, Diego. "'Los restos de un futuro que vuelve': reediciones y relecturas del pasado reciente en la crítica y la literatura argentinas contemporáneas". Cuadernos Lírico 13 (2015): 1-12. Web. 3 de agosto de 2017.

Pinda, Adriana. Parias zugun. Santiago: Lom Ediciones, 2014. Impreso.

Piper Shafir, Isabel; Fernández Droguett, Roberto e Íñiguez Rueda, Lupicinio. "Psicología social de la memoria: espacios y políticas del recuerdo". Psykhe 22. 2 (2013): 19-31. Web. 15 octubre de 2017.

Obstinaciones de la memoria: la dictadura militar chilena en las tramas del recuerdo. Tesis para optar al grado de Doctora en Psicología Social, Universidad Autónoma de Barcelona, España, 2005. Web. 1 de octubre de 2017.

Portelli, Alessandro. "Sobre los usos de la memoria: memoria-monumento, memoria involuntaria, memoria perturbadora". Sociohistórica 32 (2013): s/p. Web. 5 de octubre de 2017.

Quílez, Laia. "Hacia una teoría de la posmemoria. Reflexiones en torno a las representaciones de la memoria generacional". Historiografías: revista de historia y teoría 8 (2014): 57-75. Impreso.

Richard, Nelly. Latencias y sobresaltos de la memoria inconclusa (Chile: 1990-2017). Córdoba: Edición Universitaria Villa María, 2017. Impreso. Crítica de la memoria (1990 - 2010). Santiago: Ediciones Universidad Diego Portales, 2010. Impreso.

Sarlo, Beatriz. Tiempo pasado. Cultura de la memoria y giro subjetivo. Una discusión. Buenos Aires: Siglo XXI, 2012. Impreso.

Seguel, Leonardo. "El territorio intersticial de lo cotidiano". Urbano, 4.4 (2001): 16-19. Web. 28 de agosto de 2017.

Sepúlveda, Magda. Ciudad Quiltra. Poesía chilena (1973-2013). Santiago: Cuarto Propio, 2013. Impreso.

Smiths, Florencia. El margen del cuerpo. Santiago: Editorial Fuga, 2008. Impreso.

Vásquez, Belín y Pérez Jiménez, César. "Nuevas identidades-otras ciudadanías". Revista de Ciencias Sociales (RCS) XV. 4 (2009): 653-667. Impreso.

Waldman, Gilda. "La 'cultura de la memoria'. Problemas y reflexiones". Política y cultura, 26 (2006): 11-34. Impreso. 